\title{
Kidney Function, Kidney Function Decline, and the Risk of Dementia in Older Adults
}

\section{A Registry-Based Study}

Hong Xu, MD, PhD, Sara Garcia-Ptacek, MD, PhD, Marco Trevisan, Biostat, Marie Evans, MD, PhD, Bengt Lindholm, MD, PhD, Maria Eriksdotter, MD, PhD, and Juan Jesus Carrero, Pharm, PhD

Neurology ${ }^{\circledR}$ 2021;96:e2956-e2965. doi:10.1212/WNL.0000000000012113

\author{
Correspondence \\ Dr. Xu \\ hong.xu.2@ki.se
}

\begin{abstract}
Objective

Community-based reports regarding the association between the estimated glomerular filtration rate (eGFR) and dementia risk show conflicting results. The aim of this study is to investigate the links among kidney function, kidney function decline, and dementia incidence.
\end{abstract}

\section{Methods}

We analyzed the association of eGFR with the risk of dementia (defined as a new dementia diagnosis or initiation of dementia treatments) among 329,822 residents of Stockholm who accessed health care during 2006 to 2011, were $\geq 65$ years of age, had no history of dementia, or underwent kidney replacement therapy. We also estimated the rate of eGFR decline among 205,622 residents with repeated eGFR measurements during the first year of observation and investigated its association with subsequent dementia risk.

\section{Results}

We detected 18,983 cases of dementia (5.8\% of participants) over a median follow-up of 5 years. Dementia incidence rates were progressively higher with lower eGFR: from 6.56/1,000 person-years in those with eGFR of 90 to $104 \mathrm{~mL} / \mathrm{min}$ to 30.28/1,000 person-years in those with eGFR $<30 \mathrm{~mL} / \mathrm{min}$. After multivariable adjustment, lower eGFR was associated with a higher dementia risk (hazard ratio [HR] 1.71, 95\% confidence interval [CI] 1.54-1.91 in eGFR $30-59 \mathrm{~mL} / \mathrm{min}$; HR $2.62,95 \%$ CI 1.91-3.58 in eGFR $<30 \mathrm{~mL} / \mathrm{min}$ ) compared with eGFR of 90 to $104 \mathrm{~mL} / \mathrm{min}$. A steeper decline in eGFR (decline $>2 \mathrm{~mL} / \mathrm{min} / 1.73 \mathrm{~m}^{2} / \mathrm{y}$ ) within 1 year was associated with higher dementia risk. Risk magnitudes were stronger for vascular dementia than for Alzheimer dementia. As many as 10\% (95\% CI 6\%-14\%) of dementia cases could be attributed to eGFR $<60 \mathrm{~mL} / \mathrm{min} / 1.73 \mathrm{~m}^{2}$, a proportion higher than that attributed to other dementia risk factors such as cardiovascular disease and diabetes.

\section{Conclusions}

Both lower kidney function and steeper kidney function decline are associated with the development of dementia. 


\section{Glossary}

ACT = Adult Changes in Thought; $\mathbf{C I}=$ confidence interval; $\mathbf{C K D}=$ chronic kidney disease; eGFR = estimated glomerular filtration rate; HR = hazard ratio; HUNT = Trøndelag Health Study; ICD-10 = International Classification of Diseases, 10th revision; $\mathbf{M A S}=$ Sydney Memory and Ageing Study; PAF = population attributable fraction; $\mathbf{p y}=$ person-years; SCREAM = Stockholm Creatinine Measurements; SPRINT $=$ Systolic Blood Pressure Intervention Trial; 3C $=$ Three City.

Dementia, the progressive decline of cognition and functioning beyond that of the normal aging process, ${ }^{1}$ occurs mostly in old age, with a prevalence estimate of $5 \%$ at 65 to 74 years, $20 \%$ at 75 to 84 years, and $50 \%$ in those $>85$ years. ${ }^{2}$ Dementia is associated with increased morbidity ${ }^{3}$ and mortality, ${ }^{4}$ but there are limited treatment strategies. ${ }^{5}$ Currently, identifying potentially modifiable risk factors is the only viable strategy to prevent dementia. ${ }^{5}$

Chronic kidney disease ( $\mathrm{CKD})$, the persistent reduction in kidney function, is also very common among older adults, with a population prevalence of $25 \%$ to $40 \%$ depending on age strata. ${ }^{6}$ Even a mild reduction in kidney function, as defined by estimated glomerular filtration rate (eGFR), is associated with a markedly increased risk of comorbid conditions such as cardiovascular and cerebrovascular disease, ${ }^{7,8}$ infections, ${ }^{9}$ anemia, ${ }^{10}$ and possibly dementia. There is indeed growing evidence of a relationship between the kidneys and the brain. ${ }^{11-13}$ Some studies have shown an association among $\mathrm{CKD}$, a higher prevalence of cognitive impairment, and faster decline in cognitive function. ${ }^{14-18}$ However, previous studies on the association between kidney function and the incidence of dementia diagnosis show conflicting results ${ }^{19-29}$ that might be due to fundamental differences in, for example, methods to assess kidney function or dementia, study population (size and selection criteria), and inclusion of confounders. ${ }^{26}$

Against this background, we decided to explore the risk of dementia across the full spectrum of kidney function in a large population of Swedes $\geq 65$ years of age with serial measures of kidney function.

\section{Methods}

\section{Study Population}

We used data from the Stockholm Creatinine Measurements [SCREAM] project, a health care use cohort from the region of Stockholm, Sweden, including all residents undertaking serum creatinine tests during 2006-2011. Given the commonness of creatinine testing among the elderly, SCREAM captured $>90 \%$ of the complete population census $\geq 65$ years of age in the region. ${ }^{30}$ Laboratory data were linked with regional and national administrative databases for complete information on health care use, dispensed drugs, validated kidney replacement therapy endpoints (dialysis or transplant), and follow-up for death, with virtually no loss to follow-up. For this study, we included all participants with age $\geq 65$ years at their first available outpatient creatinine measurement, which was considered the study baseline. Exclusion criteria were any recorded history of dementia, missing information on age or sex, and undergoing kidney replacement therapy (maintenance dialysis or kidney transplantation) at cohort entry (figure e-1, doi.org/10.5061/ dryad.mw6m905wb).

\section{Standard Protocol Approvals, Registrations, and Patient Consents}

The regional Ethics Committee in Stockholm, Sweden, approved the study protocol. Patient informed consent was not deemed necessary by the ethics committee. Data were deidentified by Swedish government authorities before delivery to the research team.

\section{Exposures}

We first extracted information on all eligible creatinine measurements per individual. Eligible creatinine tests were those performed in an outpatient setting and with plausible concentrations within the range of 0.5 to $17.0 \mathrm{mg} / \mathrm{dL}$. All measurements were standardized to isotope dilution mass spectrometry standards.

The first exposure was eGFR at cohort entry (baseline), which was calculated from the first eligible creatinine for each patient with the Chronic Kidney Disease Epidemiology Collaboration creatinine equation. ${ }^{31}$ Data on ethnicity are not available in Sweden by law, and all participants were assumed to be White. We used 5 eGFR categories per $15-\mathrm{mL} / \mathrm{min} / 1.73 \mathrm{~m}^{2}$ increments using the 90 to $104 \mathrm{~mL} / \mathrm{min} / 1.73 \mathrm{~m}^{2}$ as the reference group. This is consistent with previous work showing that this is an ideal reference because it allows risk to be assessed at higher and lower eGFR. ${ }^{32,33}$

The second exposure was the rate (slope) of kidney function decline (in milliliters per minute per year), calculated from all subsequent eGFR measurements taken within 1 year $( \pm 6$ months) from the baseline measurement. We set a decrease in eGFR of $-1 \mathrm{~mL} / \mathrm{min} / 1.73 \mathrm{~m}^{2}$ per year as the reference category because this is the expected eGFR change with the normal aging process and may not be pathologic.

\section{Covariates}

Covariates were defined at baseline and included age, sex, and selected comorbid conditions and medications. Definition of comorbid conditions was based on ICD-10 codes. Diabetes, hypertension, and depression were further enriched with information on recent dispensation of related medications. Definitions of medications were based on Anatomical Therapeutic Chemical codes (table e-1, doi.org/10.5061/dryad. mw6m905wb). 


\section{Follow-up and Study Outcome}

The primary study outcome was the first recorded diagnosis of all-cause dementia or the initiation of antidementia drugs (donepezil, rivastigmine, galantamine, memantine). The secondary study outcomes were the first recorded diagnosis of Alzheimer dementia and vascular dementia. These and other definitions are detailed in table e-2 (doi.org/10.5061/dryad. mw6m905wb), but we recognize that the validity of these diagnoses may be low. Participants were censored at the end of follow-up (December 31, 2012), death, or migration from the region, whichever occurred first. Death date was obtained from the National Board of Health and Welfare's Cause of Death register (socialstyrelsen.se). The rest of the information was obtained from complete health care records in the region or dispensation at Swedish pharmacies, with presumably no loss to follow-up.

\section{Data Analysis}

Continuous variables were reported as mean \pm SD and categorical variables as counts and percentages. Baseline characteristics were compared across different eGFR categories by analysis of variance for continuous variables and Pearson $\chi^{2}$ for percentages.

The incidence of all-cause dementia was assessed by the Kaplan-Meier method, and we also calculated incidence rates with $95 \%$ confidence intervals (CIs) using the exact method. The proportional hazards assumption was checked with the Schoenfeld residuals test. In the case of violation of the proportionality assumption for covariates, flexible parametric survival models (Royston-Parmar models) were performed to study the association between eGFR and dementia, with attained (chronologic) age as the underlying timescale to better capture the impact of old age on both exposure and outcome. Stepwise adjustments were performed for (1) sex, unhealthy life style diagnoses, and comorbid conditions (2) and medications. We included medications separately from diagnoses because we believe that adds confounding. For example, medications may have various indications (e.g., angiotensinconverting enzyme inhibitor/angiotensin receptor blockers can be used to treat hypertension but also to manage albuminuria in kidney disease) and may add information on the severity of the comorbidity (e.g., hypertension managed with 3 medications is worse than hypertension managed with only 1 medication). We also investigated associations between eGFR and dementia risk using piecewise linear splines, with knots fixed every 15 $\mathrm{mL} / \mathrm{min} / 1.73 \mathrm{~m}^{2}$ of eGFR.

The weighted contributions of CKD (eGFR $<60 \mathrm{~mL} / \mathrm{min}$ / $1.73 \mathrm{~m}^{2}$ ) and other comorbid conditions to the risk of incident dementia were quantified with the population attributable fraction (PAF) with the following equation: PAF = $1-\frac{1-S_{0}(t)}{1-S(t)}$, where $S_{0}(t)$ denotes the counterfactual survival function for the dementia event if the exposure would have been eliminated from the population at baseline and $S(t)$ denotes the factual survival function. ${ }^{34}$ The estimates of PAF were adjusted for the abovementioned covariates.
A number of sensitivity analyses were performed to test the robustness of results. First, to explore the possibility of detection bias and reverse causality, we excluded dementia events within the first 2 years of follow-up, in recognition of previous work showing that this is the average time difference between dementia onset and first registry of dementia code. ${ }^{35}$ Second, we explored the association between eGFR categories and all-cause dementia risk in prespecified strata, including sex, age, and presence (versus absence) of selected comorbid conditions.

For those participants who had $>1$ outpatient eGFR measurement taken within the first year of data collection, we estimated their rate of kidney function decline (eGFR slope) using mixed-effects repeated-measures models of unstructured variance-covariance matrix, random intercept, and random slope. The models were adjusted for baseline eGFR, age, sex, baseline comorbid conditions, and medications. As a next step, we used flexible parametric survival models to relate the eGFR slope to the subsequent dementia risk, and attained age was again set as the underlying timescale. After the exclusion of participants developing dementia during the first year, time at risk began on the date of the last creatinine used to estimate the eGFR slope (new baseline). eGFR slope was introduced as a linear spline with knots at $-3,-1,0$, and $1 \mathrm{~mL} /$ $\min / \mathrm{y}$. The model further adjusted for sex, new baseline eGFR, comorbid conditions, and medications. There were no missing variables to report, and analyses were performed with R (r-project.org, Vienna, Austria) and Stata version 16.0 (StataCorp, College Station, TX).

\section{Data Availability}

SCREAM study data are stored at the Department of Medical Epidemiology and Biostatistics at Karolinska Institutet (ki.se/ meb) and can be made available to interested researchers for collaborative projects on request.

Supplementary data are available from Dryad (tables e-1-e-9, figure e-1-e-3): doi.org/10.5061/dryad.mw6m905wb.

\section{Results}

\section{Baseline Characteristics}

There were $\approx 1.3$ million Stockholm citizens accessing health care and undergoing creatinine testing between 2006 and 2011. After exclusion criteria were applied (figure e-1, doi. org/10.5061/dryad.mw6m905wb), the study cohort consisted of 329,822 participants free from dementia history and $\geq 65$ years of age. Their mean age was $74 \pm 8$ years, and $56 \%$ were women (table 1). Mean eGFR was $75 \pm 17 \mathrm{~mL} / \mathrm{min}$; $0.6 \%$ of participants had eGFR $\geq 105 \mathrm{~mL} / \mathrm{min}, 20 \%$ had eGFR of 90 to $104 \mathrm{~mL} / \mathrm{min}, 61 \%$ had eGFR of 60 to $89 \mathrm{~mL} / \mathrm{min}$, $17 \%$ had eGFR of 30 to $59 \mathrm{~mL} / \mathrm{min}$, and $1.5 \%$ had eGFR $<30$ $\mathrm{mL} / \mathrm{min}$. The most common comorbidity was hypertension (40\%), followed by cancer (17\%), diabetes mellitus (12\%), depression (12\%), atrial fibrillation (11\%), congestive heart 
Table 1 Baseline Characteristics of Study Participants $\geq 65$ Years of Age, Overall and by eGFR Strata

\begin{tabular}{|c|c|c|c|c|c|c|c|}
\hline & \multirow[b]{2}{*}{$\begin{array}{l}\text { Overall } \\
(n=329,822)\end{array}$} & \multicolumn{5}{|c|}{ eGFR strata, $\mathrm{mL} / \mathrm{min} / 1.73 \mathrm{~m}^{2}$} & \multirow[b]{2}{*}{$p$ Value } \\
\hline & & $\begin{array}{l}\text { eGFR } \geq 105 \\
(n=1,891)\end{array}$ & $\begin{array}{l}\text { eGFR 90-104 } \\
(n=67,211)\end{array}$ & $\begin{array}{l}\text { eGFR 60-89 } \\
(n=200,927)\end{array}$ & $\begin{array}{l}\text { eGFR } 30-59 \\
(n=54,950)\end{array}$ & $\begin{array}{l}\text { eGFR <30 } \\
(n=4,843)\end{array}$ & \\
\hline eGFR, mean $\pm S D, \mathrm{~mL} / \mathrm{min} / 1.73 \mathrm{~m}^{2}$ & $75 \pm 17$ & $109 \pm 5$ & $94 \pm 3$ & $77 \pm 9$ & $50 \pm 8$ & $23 \pm 6$ & $<0.001$ \\
\hline Age strata, mean $\pm S D, y$ & $74 \pm 8$ & $67 \pm 4$ & $68 \pm 4$ & $74 \pm 8$ & $80 \pm 8$ & $82 \pm 9$ & $<0.001$ \\
\hline $65-<70, \mathrm{n}(\%)$ & $141,818(43.0)$ & $1,557(82.3)$ & $53,251(79.2)$ & 78,221 (38.9) & $8,214(14.9)$ & $575(11.9)$ & $<0.001$ \\
\hline $70-<75, \mathrm{n}(\%)$ & $58,262(17.7)$ & $224(11.8)$ & $9,754(14.5)$ & $41,203(20.5)$ & $6,652(12.1)$ & $429(8.9)$ & \\
\hline $75-<80, \mathrm{n}(\%)$ & $48,832(14.8)$ & $81(4.3)$ & $3,066(4.6)$ & $35,473(17.7)$ & $9,575(17.4)$ & $637(13.2)$ & \\
\hline $80-<85, \mathrm{n}(\%)$ & $40,486(12.3)$ & $24(1.3)$ & $890(1.3)$ & $26,212(13.0)$ & $12,334(22.4)$ & $1,026(21.2)$ & \\
\hline$\geq 85, \mathrm{n}(\%)$ & $40,424(12.3)$ & $5(0.3)$ & $250(0.4)$ & $19,818(9.9)$ & $18,175(33.1)$ & $2,176(44.9)$ & \\
\hline Women, n (\%) & $184,107(55.8)$ & $701(37.1)$ & $34,631(51.5)$ & $112,187(55.8)$ & $33,866(61.6)$ & $2,722(56.2)$ & $<0.001$ \\
\hline Tobacco abuse, $\mathbf{n}(\%)$ & $1,427(0.4)$ & $35(1.9)$ & $386(0.6)$ & $682(0.3)$ & $217(0.4)$ & $29(0.6)$ & $<0.001$ \\
\hline Alcohol abuse, $n$ (\%) & $8,640(2.6)$ & $342(18.1)$ & $3,165(4.7)$ & $4,119(2.0)$ & 919 (1.7) & $95(2.0)$ & $<0.001$ \\
\hline Obesity, n (\%) & $3,463(1.0)$ & $44(2.3)$ & $967(1.4)$ & $1,746(0.9)$ & $612(1.1)$ & $94(1.9)$ & $<0.001$ \\
\hline \multicolumn{8}{|l|}{ Comorbid conditions, n (\%) } \\
\hline Hypertension & $131,743(39.9)$ & $639(33.8)$ & $22,919(34.1)$ & $76,004(37.8)$ & $29,154(53.1)$ & $3,027(62.5)$ & $<0.001$ \\
\hline Diabetes mellitus & $39,514(12.0)$ & $338(17.9)$ & $7,950(11.8)$ & $20,969(10.4)$ & $9,026(16.4)$ & $1,231(25.4)$ & $<0.001$ \\
\hline Congestive heart failure & $31,135(9.4)$ & $132(7.0)$ & $2,344(3.5)$ & $14,189(7.1)$ & $12,355(22.5)$ & $2,115(43.7)$ & $<0.001$ \\
\hline Myocardial infarction & $21,882(6.6)$ & $97(5.1)$ & $2,589(3.9)$ & $11,350(5.6)$ & $6,737(12.3)$ & $1,109(22.9)$ & $<0.001$ \\
\hline Stroke & $24,096(7.3)$ & $184(9.7)$ & $3,125(4.6)$ & $12,958(6.4)$ & $6,921(12.6)$ & $694(14.3)$ & $<0.001$ \\
\hline Atrial fibrillation & $34,616(10.5)$ & $137(7.2)$ & $3,448(5.1)$ & $18,887(9.4)$ & $10,849(19.7)$ & $908(18.7)$ & $<0.001$ \\
\hline Cancer & $55,890(16.9)$ & $341(18.0)$ & $9,765(14.5)$ & $33,249(16.5)$ & $11,361(20.7)$ & $1,295(26.7)$ & $<0.001$ \\
\hline Depression & $40,217(12.2)$ & $349(18.5)$ & $8,166(12.1)$ & $22,988(11.4)$ & $7,954(14.5)$ & $760(15.7)$ & $<0.001$ \\
\hline Hearing loss & $25,476(7.7)$ & $107(5.7)$ & $4,070(6.1)$ & $15,711(7.8)$ & $5,123(9.3)$ & $465(9.6)$ & $<0.001$ \\
\hline \multicolumn{8}{|l|}{ Medications, n (\%) } \\
\hline ACEi/ARBS & $93,789(28.4)$ & $433(22.9)$ & $17,213(25.6)$ & $53,284(26.5)$ & $20,708(37.7)$ & $2,151(44.4)$ & $<0.001$ \\
\hline$\beta$-Blocking agents & $99,104(30.0)$ & $449(23.7)$ & $15,535(23.1)$ & $57,542(28.6)$ & $23,189(42.2)$ & $2,389(49.3)$ & $<0.001$ \\
\hline Calcium channel blockers & $52,725(16.0)$ & $277(14.6)$ & $9,582(14.3)$ & $30,819(15.3)$ & $10,826(19.7)$ & $1,221(25.2)$ & $<0.001$ \\
\hline NSAIDs & $123,771(37.5)$ & $588(31.1)$ & $22,207(33.0)$ & $73,472(36.6)$ & $25,266(46.0)$ & $2,238(46.2)$ & $<0.001$ \\
\hline Statins & $79,950(24.2)$ & 352 (18.6) & $15,973(23.8)$ & $47,946(23.9)$ & $14,396(26.2)$ & $1,283(26.5)$ & $<0.001$ \\
\hline
\end{tabular}

Abbreviations: ACEi/ARB = angiotensin-converting enzyme inhibitor/angiotensin receptor blocker; eGFR = estimated glomerular filtration rate; NSAID = nonsteroidal anti-inflammatory drug.

failure (9\%), stroke (7\%), and myocardial infarction (7\%) (table 1).

\section{Incidence Rate and Hazard Ratios of Dementia Across eGFR Strata}

Over a median follow-up of 5 years, 18,983 cases of dementia (affecting 5.8\% of the participants) were detected throughout $1,185,304$ person-years (py). The overall incidence rate was $16.0 / 1,000$ py. Higher incident rates were noted for participants with CKD stage 3 or greater (6.56 per 1,000 py in eGFR
$90-104 \mathrm{~mL} / \mathrm{min}$ [reference group], 15.74 per 1,000 py in eGFR $60-89 \mathrm{~mL} / \mathrm{min}, 26.8$ per 1,000 py in eGFR $30-59 \mathrm{~mL} /$ min, and 30.3 per 1,000 py in eGFR $<30 \mathrm{~mL} / \mathrm{min}$ separately). The most common dementia diagnosis type was Alzheimer dementia (incident rate $6.36 / 1,000$ py, $2.3 \%$ of all participants and $40 \%$ of all-cause dementia events), followed by vascular dementia $(3.12 / 1000$ py, $1.1 \%$ of all participants and $20 \%$ of all-cause dementia events). In general, the incidence rate of Alzheimer dementia and vascular dementia increased across lower eGFR categories, except in the category eGFR $<30 \mathrm{~mL} /$ 
Table 2 Incidence Rate and HRs (With 95\% Cls) of Dementia Associated With Baseline eGFR Strata

\begin{tabular}{|c|c|c|c|c|c|c|c|}
\hline \multirow[b]{2}{*}{ eGFR strata, $\mathrm{mL} / \mathrm{min} / 1.73 \mathrm{~m}^{2}$} & \multirow[b]{2}{*}{ Person-years } & \multirow[b]{2}{*}{ Cases } & \multirow[b]{2}{*}{ Incidence rate per 1,000 py } & \multicolumn{2}{|l|}{ Model 1} & \multicolumn{2}{|l|}{ Model 2} \\
\hline & & & & $\mathrm{HR}(95 \% \mathrm{Cl})$ & $p$ Value & HR $(95 \% \mathrm{Cl})$ & $p$ Value \\
\hline \multicolumn{8}{|l|}{ All-cause dementia } \\
\hline Overall $(n=329,822)$ & $1,185,304$ & 18,983 & 16.02 & - & - & - & - \\
\hline$\geq 105(n=1,891)$ & 5,120 & 44 & 8.59 & $1.30(0.90-1.87)$ & 0.16 & $1.30(0.90-1.87)$ & 0.17 \\
\hline $90-104(n=67,211)$ & 221,835 & 1,456 & 6.56 & $\operatorname{REF}(1.00)$ & - & $\operatorname{REF}(1.00)$ & - \\
\hline $60-89(n=200,927)$ & 746,035 & 11,746 & 15.74 & $1.15(1.07-1.25)$ & $<0.001$ & $1.16(1.08-1.26)$ & $<0.001$ \\
\hline $30-59(n=54,950)$ & 199,332 & 5,344 & 26.81 & $1.64(1.47-1.83)$ & $<0.001$ & $1.71(1.54-1.91)$ & $<0.001$ \\
\hline$<30(n=4,843)$ & 12,981 & 393 & 30.28 & $2.44(1.79-3.34)$ & $<0.001$ & $2.62(1.91-3.58)$ & $<0.001$ \\
\hline \multicolumn{8}{|l|}{ Alzheimer dementia } \\
\hline Overall $(n=329,822)$ & $1,206,539$ & 7,663 & 6.35 & - & - & - & - \\
\hline$\geq 105(n=1,891)$ & 5,180 & 12 & 2.32 & $0.76(0.37-1.59)$ & 0.47 & $0.76(0.37-1.59)$ & 0.47 \\
\hline $90-104(n=67,211)$ & 223,599 & 650 & 2.91 & $\operatorname{REF}(1.00)$ & - & $\operatorname{REF}(1.00)$ & \\
\hline $60-89(n=200,927)$ & 759,161 & 5,155 & 6.79 & $1.32(1.18-1.48)$ & $<0.001$ & $1.33(1.18-1.49)$ & $<0.001$ \\
\hline $30-59(n=54,950)$ & 205,249 & 1,750 & 8.53 & $1.76(1.49-2.07)$ & $<0.001$ & $1.81(1.54-2.14)$ & $<0.001$ \\
\hline$<30(n=4,843)$ & 13,349 & 96 & 7.19 & $1.65(0.90-3.00)$ & 0.10 & $1.73(0.95-3.16)$ & 0.07 \\
\hline \multicolumn{8}{|l|}{ Vascular dementia } \\
\hline Overall $(n=329,822)$ & $1,214,399$ & 3,786 & 3.12 & - & - & - & - \\
\hline$\geq 105(n=1,891)$ & 5,188 & 10 & 1.93 & $2.00(1.02-3.95)$ & 0.04 & $2.01(1.02-3.96)$ & 0.04 \\
\hline $90-104(n=67,211)$ & 224,276 & 284 & 1.27 & $\operatorname{REF}(1.00)$ & - & $\operatorname{REF}(1.00)$ & - \\
\hline $60-89(n=200,927)$ & 764,885 & 2,295 & 3.00 & $1.20(1.01-1.43)$ & 0.04 & $1.20(1.01-1.43)$ & 0.04 \\
\hline $30-59(n=54,950)$ & 206,679 & 1,114 & 5.39 & $2.11(1.70-2.63)$ & $<0.001$ & $2.12(1.70-2.64)$ & $<0.001$ \\
\hline$<30(n=4,843)$ & 13,371 & 83 & 6.21 & $2.56(1.42-4.63)$ & 0.002 & $2.61(1.44-4.73)$ & 0.002 \\
\hline
\end{tabular}

Abbreviations: $\mathrm{Cl}$ = confident interval; eGFR = estimated glomerular filtration rate; $\mathrm{HR}$ = hazard ratio; py = person-year; REF = referent.

Flexible parametric survival models with attained age as the underlying timescale were used for the calculation of HRs and their corresponding $95 \%$ Cls. Model 1 was adjusted for sex, chronic smoking, alcohol abuse, diagnosed obesity, and comorbid conditions (hypertension, diabetes, congestive heart failure, myocardial infarction, stroke, atrial fibrillation, cancer history, depression, and hearing loss). Model 2 was further adjusted for medications (use of angiotensin-converting enzyme inhibitor/angiotensin receptor blockers, $\beta$-blocking agents, calcium channel blockers, nonsteroidal anti-inflammatory drugs, and statins).

min for Alzheimer dementia (s-figure e-2 and s-table e-3, doi. org/10.5061/dryad.mw6m905wb). Kaplan-Meier curves suggested higher all-cause dementia risk in participants with lower eGFR categories (s-figure e-3).

Next, we studied whether the higher incidence rates across eGFR strata were explained by accompanying comorbid conditions and characteristics through multivariable-adjusted survival models, selecting eGFR of 90 to $104 \mathrm{~mL} / \mathrm{min}$ as the reference category. A J-shaped association was observed between eGFR and the risk of all-cause dementia, both when eGFR categories were examined (table 2) and when eGFR was modeled as a continuous metric using splines (figure 1). Compared to participants with eGFR of 90 to $104 \mathrm{~mL} / \mathrm{min}$, participants with eGFR of 60 to $89 \mathrm{~mL} / \mathrm{min}$ had a slightly higher dementia risk $(1.16[1.08-1.26], p<0.001)$, and those with eGFR of $30-59$ and $<30 \mathrm{~mL} / \mathrm{min}$ had $71 \%(1.71$ $[1.54-1.91], p<0.001)$ and $162 \%(2.62[1.91-3.58], p<$ $0.001)$ higher risk of incident all-cause dementia, respectively (table 2).

Hazard ratios (HRs) for Alzheimer dementia and vascular dementia are shown in table 2. Across lower eGFR categories, we observed a gradually higher risk of Alzheimer dementia and vascular dementia (2.12 [1.70-2.64], $p<0.001$ in eGFR $30-59 \mathrm{~mL} / \mathrm{min}$ and 2.61 [1.44-4.73], $p=0.002$ in eGFR $<30$ $\mathrm{mL} / \mathrm{min}$ for vascular dementia; 1.81 [1.54-2.14], $p<0.001$ in eGFR $30-59 \mathrm{~mL} / \mathrm{min}$ and 1.73 [0.95-3.16], $p=0.07$ in eGFR $<30 \mathrm{~mL} / \mathrm{min}$ for Alzheimer dementia). Compared to participants with eGFR of 90 to $104 \mathrm{~mL} / \mathrm{min}$, those with eGFR $\geq 105 \mathrm{~mL} / \mathrm{min}$ had a higher risk of vascular dementia (2.01 [1.02-3.96], $p=0.04)$ but not Alzheimer dementia. 
Figure 1 Risk of Dementia Associated With Baseline eGFR
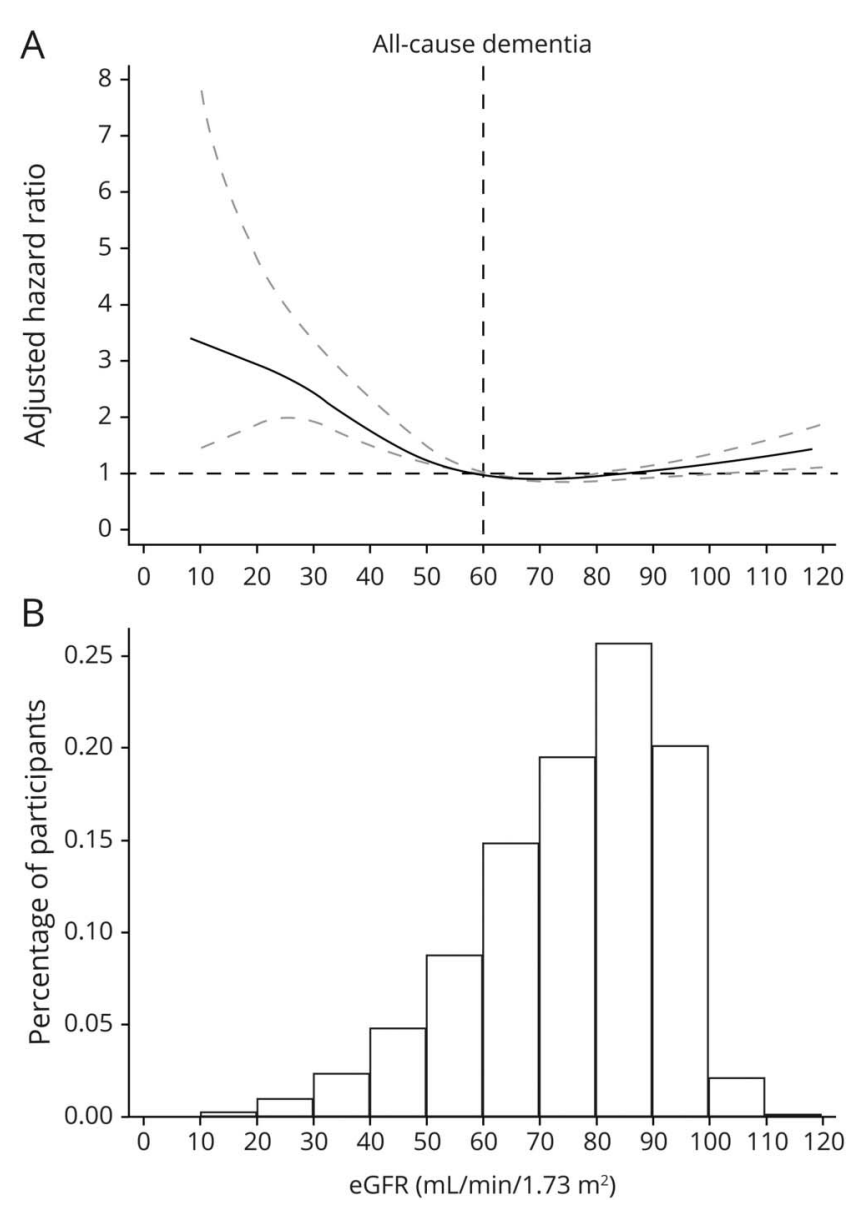

(A) Hazard ratios (HRs) for all-cause dementia risk by estimated glomerular filtration rate (eGFR; per 1-ml/min/1.73 $\mathrm{m}^{2}$ increase, continuous variable) using linear splines. Model adjusted for sex, chronic smoking, alcohol abuse, diagnosed obesity, comorbid conditions (hypertension, diabetes, congestive heart failure, myocardial infarction, stroke, atrial fibrillation, cancer history, depression, and hearing loss), and medications (use of angiotensin-converting enzyme inhibitor/angiotensin receptor blockers, $\beta$-blocking agents, calcium channel blockers, nonsteroidal anti-inflammatory drugs, and statins). Knots were set every $15 \mathrm{~mL} / \mathrm{min} / 1.73 \mathrm{~m}^{2}$ of eGFR, rendering the same eGFR categories as in table 1. Data were reported as HRs and 95\% confidence intervals (dashed lines). (B) Percentage of participants $(n=329,822)$ across eGFR levels.

\section{Plausible Risks Factors and PAF}

People who developed dementia had a higher prevalence of comorbid conditions at baseline (table 3). Plausible comorbid risk factors for dementia were explored in multivariable analysis. The HR of dementia risk was highest for the presence of CKD (eGFR <60 mL/min; HR 1.49 [1.23-1.80] $p<$ $0.001)$, followed by having a history of depression (1.49 [1.38-1.62], $p<0.001)$, stroke (1.41 [1.35-1.48], $p<0.001)$, diabetes (1.22 [1.16-1.27], $p<0.001)$, atrial fibrillation $(1.10$ [1.05-1.15], $p<0.001)$, and myocardial infarction (1.08 [1.02-1.14], $p=0.01)$. The presence of diagnosed hypertension and a history of cancer (0.95 [0.92-0.99], $p=0.01$; and 0.87 [0.84-0.90], $p<0.001$ respectively) were associated with a lower dementia risk, and there was no significant association between congestive heart failure and the risk of dementia in our cohort. The use of renin-angiotensin system inhibitors, $\beta$-blocking agents, calcium channel blockers, and statins at baseline also was associated with a lower HR of dementia and negative PAFs (table e-4, doi.org/10.5061/ dryad.mw6m905wb).

Via PAF analyses we estimated that 10\% (95\% CI 6\%-14\%) of the dementia cases could be attributed to eGFR $<60 \mathrm{~mL} /$ min, followed by depression (7\% of cases attributed, 95\% CI $5 \%-8 \%$ ), stroke (4\% of cases, $95 \%$ CI $3 \%-4 \%$ ) and diabetes ( $2 \%$ of cases, $95 \%$ CI $2 \%-3 \%$ ). PAFs were $\approx 1 \%$ for comorbid conditions such as atrial fibrillation and myocardial infarction (table 3).

\section{Sensitivity and Subgroup Analyses}

We explored potential reverse causation and detection biases by excluding events within the first 2 years of follow-up and still observed associations similar to our main analysis for the lower eGFR strata. Conversely, no association was observed for those with eGFR $\geq 105 \mathrm{~mL} / \mathrm{min}$ for all-cause dementia (table e-5, doi.org/10.5061/dryad.mw6m905wb). Stratified analyses are shown in s-tables e-6 and e-7 (doi.org/10.5061/ dryad.mw6m905wb). Among all prespecified subgroups, there was suggestion of heterogeneity with lack of association between eGFR and dementia risk in patients $\geq 75$ years of age.

\section{Associations Between the Rate of eGFR Decline and the Risk of Dementia}

There were 205,622 participants (62\% of the initial population) who had at least 2 eGFR measurements within the first year of data collection. These individuals were included in the analysis of eGFR change in regard to dementia risk. The median number of plasma creatinine measurements per individual used to calculate the eGFR slope was 3 (interquartile range 2-4), ranging from 2 to 17 . During a mean subsequent follow-up of 4.5 years, there were 11,175 cases of all-cause dementia, 4,692 cases of Alzheimer dementia, and 2,495 cases of vascular dementia. The mean eGFR slope was $-1.17 \mathrm{~mL} /$ $\min / \mathrm{y}(95 \% \mathrm{CI}-1.29$ to $-1.05, p=0.01)$ (table e-8, doi.org/ 10.5061/dryad.mw6m905wb).

In multivariable-adjusted analyses, a steeper eGFR decline was associated with a higher risk of all-cause dementia (figure 2), with statistically significant associations for declines $>2 \mathrm{~mL} / \mathrm{min} / \mathrm{y}$ (table e-9, doi.org/10.5061/dryad.mw6m905wb). Similar associations, but stronger in magnitude, were also observed between the rate of eGFR decline and the risk of vascular dementia. Less clear association was observed for Alzheimer dementia (table e-9, doi.org/10.5061/dryad.mw6m905wb).

\section{Discussion}

This study identifies CKD as a possible risk factor for dementia. In a large register-based cohort of older adults, both lower kidney function and steeper kidney function decline were consistently associated with the risk of dementia diagnosis, particularly vascular dementia. Assuming a direct association, our analysis suggests that $10 \%$ of the dementia 
Table 3 Adjusted HR and PAF With Incidence of All-Cause Dementia Risk With Baseline Comorbidities

\begin{tabular}{|c|c|c|c|c|c|c|}
\hline Comorbidities & $\begin{array}{l}\text { Percent in patients not developing } \\
\text { dementia }(n=310,839)\end{array}$ & $\begin{array}{l}\text { Percent in patients developing } \\
\text { dementia }(n=18,983)\end{array}$ & $\begin{array}{l}\text { Adju } \\
(95 \%\end{array}$ & $\begin{array}{l}\text { sted HR } \\
\mathrm{CI})\end{array}$ & $\begin{array}{l}p \\
\text { Value }\end{array}$ & $\begin{array}{l}\text { PAF }(95 \% \\
\text { CI), } \%^{a}\end{array}$ \\
\hline $\begin{array}{l}\text { eGFR }<60 \mathrm{~mL} / \mathrm{min} / \\
1.73 \mathrm{~m}^{2}\end{array}$ & 17.4 & 30.2 & 1.49 & $1.23-1.80$ & $<0.001$ & 10 (6 to 14$)$ \\
\hline Hypertension & 39.9 & 40.5 & 0.95 & $0.92-0.99$ & 0.01 & $-2(-3$ to -1$)$ \\
\hline Diabetes & 11.9 & 13.4 & 1.22 & $1.16-1.27$ & $<0.001$ & 2 (2 to 3 ) \\
\hline $\begin{array}{l}\text { Congestive heart } \\
\text { failure }\end{array}$ & 9.1 & 14.5 & 1.03 & $0.98-1.08$ & 0.24 & $0.4(-0.3$ to 1$)$ \\
\hline $\begin{array}{l}\text { Myocardial } \\
\text { infarction }\end{array}$ & 6.5 & 8.2 & 1.08 & $1.02-1.14$ & 0.01 & 0.6 (0.1 to 1$)$ \\
\hline Stroke & 4.3 & 5.7 & 1.41 & $1.35-1.48$ & $<0.001$ & 4 (3 to 4$)$ \\
\hline Atrial fibrillation & 7.0 & 13.1 & 1.10 & $1.05-1.15$ & $<0.001$ & 1 (1 to 2 ) \\
\hline Cancer & 10.2 & 15.6 & 0.87 & $0.84-0.90$ & $<0.001$ & $-3(-3$ to -2$)$ \\
\hline Depression & 11.7 & 20.0 & 1.49 & $1.38-1.62$ & $<0.001$ & 7 (5 to 8$)$ \\
\hline Hearing loss & 7.6 & 9.5 & 1.01 & $0.97-1.06$ & 0.57 & $\begin{array}{l}0.1(-0.3 \text { to } \\
0.6)\end{array}$ \\
\hline
\end{tabular}

Abbreviations: $\mathrm{Cl}$ = confident interval; eGFR = estimated glomerular filtration rate; $\mathrm{HR}$ = hazard ratio; PAF = population attributable fraction.

a Model further adjusted for sex, chronic smoking, alcohol abuse, diagnosed obesity and medications (use of angiotensin-converting enzyme inhibitor/ angiotensin receptor blockers, $\beta$-blocking agents, calcium channel blockers, nonsteroidal anti-inflammatory drugs, and statins).

cases could be attributed to $\mathrm{CKD}$, a proportion higher than that observed for other well-established dementia risk factors such as cardiovascular disease and diabetes.

Our principal finding is an inverse linear association between baseline kidney function and dementia incidence in $>325,000$ participants. This is, to the best of our knowledge, the largest study to date on the matter, exceeding by several-fold the sample size of all previous studies combined and evaluating the whole spectrum of kidney function. Such results are not novel but may help reconcile the disagreement in previous literature potentially attributed to small sample sizes and dichotomization of kidney function. Our study agrees with and expands on several previous population-based longitudinal studies. First, 2 Japanese studies with collectively 830 older participants reported an increased dementia risk during a mean follow-up of 7 years in individuals with baseline eGFR $<60 \mathrm{~mL} / \mathrm{min}^{20,21}$ A more recent Japanese study ( $\mathrm{n}=1,562$ participants $\geq 60$ years of age) also observed a higher dementia risk in participants with eGFR $<60 \mathrm{~mL} / \mathrm{min} .{ }^{27}$ Furthermore, the Cardiovascular Health Cognition Study, which recruited 3,349 elderly participants, observed a $37 \%$ increase in the risk for dementia incidence and elevated serum creatinine at baseline, but not eGFR, during a mean follow-up of 6 years. ${ }^{19}$ Finally, in the Uppsala Longitudinal Study of Adult Men ( $\mathrm{n}=$ 1,153), the 11-year risk of Alzheimer dementia also increased with lower eGFR. ${ }^{22}$ In our study, the increased risks observed were stronger for vascular than for Alzheimer dementia, an observation that also agrees with 2 of these previous reports ${ }^{19,27}$ but is inconsistent with another ${ }^{20}$ and was not addressed in the remaining studies. ${ }^{21,22}$
Our findings, however, disagree with several previous studies. First, the French population-based Three-City (3C) study included 7,839 older participants undergoing dementia screening and did not show increased dementia risks for persons with eGFR $<60 \mathrm{~mL} / \mathrm{min}$ at baseline $(\mathrm{n}=954)$, although the stratum of eGFR of 45 to $60 \mathrm{~mL} / \mathrm{min}$ was associated with increased incidence of vascular dementia. ${ }^{23}$ Second, the US Adult Changes in Thought (ACT; $\mathrm{n}=2,968$ ) study found no statistical differences across baseline eGFR strata $(\mathrm{n}=1,226$ with $\mathrm{eGFR}<60 \mathrm{~mL} / \mathrm{min}$ ) and the risk of dementia. ${ }^{25}$ In the Sydney Memory and Ageing Study (MAS, $\mathrm{n}=889$ ), individuals with lower eGFR ( $\mathrm{n}=296$ with eGFR $<60 \mathrm{~mL} / \mathrm{min}$ ) had a decreased risk of cognitive decline or dementia incidence; however, individuals with lower eGFR were more often lost to follow-up. ${ }^{24}$ Finally, in the Systolic Blood Pressure Intervention Trial (SPRINT; $\mathrm{n}=8,563$ hypertensive adults, age $\geq 50$ years), baseline eGFR $<60 \mathrm{~mL} / \mathrm{min}$ and baseline albuminuria were not associated with risk for dementia during median 5.1 years of follow-up; however, there was an increased risk for probable dementia or MCI among participants with baseline eGFR of $45 \mathrm{~mL} / \mathrm{min}^{36}$ The discrepancy between these reports and our study might be explained by differences in study design (screening vs health care extraction) and outcome ascertainment (neuropsychologist performance vs ICD diagnoses/drug dispensations). However, we believe that these previous studies included insufficient numbers of patients with low kidney function, limiting their power to find differences in those ranges. The Norwegian population-based Trøndelag Health Study (HUNT; $\mathrm{n}=47,840$ ) found no association between eGFR and dementia. ${ }^{28}$ However, it included participants who were 
Figure 2 Risk of Dementia Associated With Rate of Kidney Function Decline

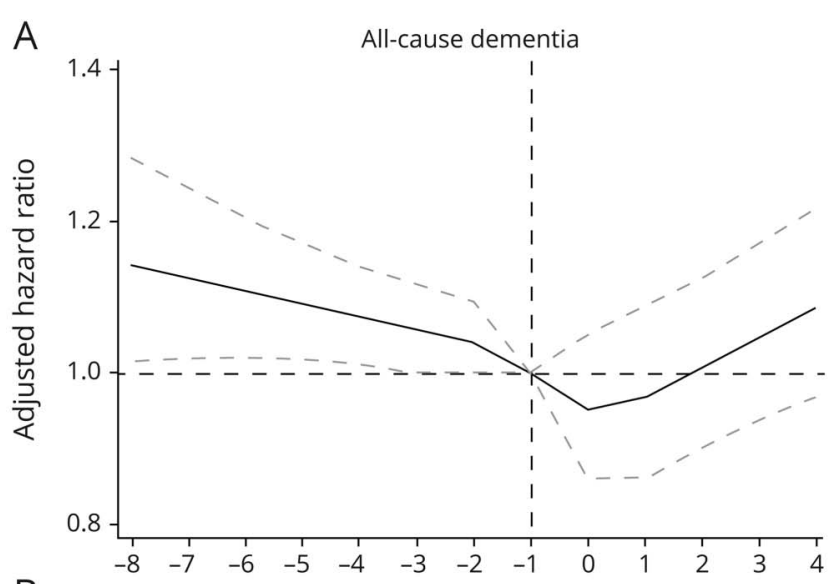

B

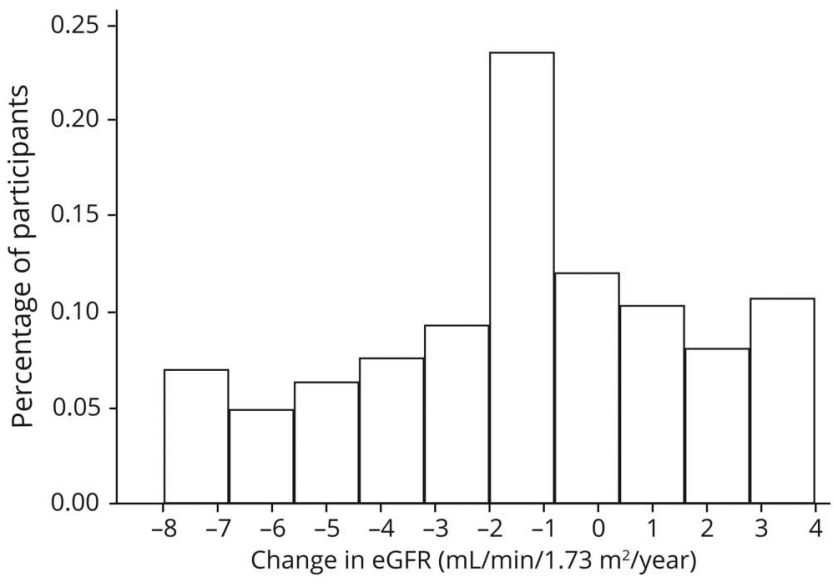

(A) Hazard ratios (HRs) for all-cause dementia risk by the rate of kidney function decline (estimated glomerular filtration rate [eGFR] slope per ml/ $\mathrm{min} / 1.73 \mathrm{~m}^{2}$, continuous variable) using linear splines. Model adjusted for baseline eGFR, sex, chronic smoking, alcohol abuse, diagnosed obesity, comorbid conditions (hypertension, diabetes, congestive heart failure, myocardial infarction, stroke, atrial fibrillation, cancer history, depression, and hearing loss), and medications (use of angiotensin-converting enzyme inhibitor/angiotensin receptor blockers, $\beta$-blocking agents, calcium channel blockers, nonsteroidal anti-inflammatory drugs, and statins). Knots were set at $-3,-1,0$, and $1 \mathrm{~mL} / \mathrm{min} / \mathrm{y}$. Data were reported as $\mathrm{HRs}$ and $95 \%$ confidence intervals (dashed lines). (B) Percentage of participants $(n=205,622)$ across eGFR slope values.

on average 49 years old, which could explain the low proportion of cases with CKD and low number of incident dementia cases $(n=668)$. Nonetheless, the observation that albuminuria, a marker of early kidney damage, consistently predicted dementia risk offers indirect support to our hypothesis.

Lending credibility to our primary observation, we also report an association between the 1-year rate of kidney function decline and the subsequent (all-cause and vascular) dementia risk among $>200,000$ patients with repeated creatinine assessments in routine care. Several previous studies have also explored the association between categories of eGFR change and dementia. In the SPRINT study $(\mathrm{n}=8,563)$, declining kidney function measured by eGFR $>30 \%$ was associated with increased risk for probable dementia, independently of the intensity of antihypertensive. ${ }^{36}$ In a subset $(n=2,382)$ of participants from the 3C study, a steeper in decline eGFR during the first 4 years of follow-up was associated with higher risk for all-cause and vascular dementia but not for Alzheimer dementia. ${ }^{23}$ However, the ACT study $(\mathrm{n}=2,968)$ failed to observe any association between eGFR decline within 6 years and risk of dementia. ${ }^{25}$

We noted the higher end of eGFR $(\geq 105 \mathrm{~mL} / \mathrm{min})$ in our population, and the few participants who appeared to have increased their kidney function during the first year were also at increased risk for all-cause and vascular dementia. This should not be interpreted as higher kidney function/kidney function improvement conferring increased risk. We attribute it to the inherent error of eGFR measurements in the context of other underlying diseases. In our data from routine care, higher eGFR measures most likely represent inaccurate estimations of true GFR caused by low serum creatinine, which usually accompanies conditions of reduced muscle mass or chronic illness. ${ }^{37}$ Body weight loss and malnutrition often precede dementia diagnosis, ${ }^{38,39}$ and these conditions may also affect the eGFR estimations. ${ }^{40}$ On the other hand, we cannot exclude the possibility that patients with eGFR $\geq 105$ $\mathrm{mL} / \mathrm{min}$ may de facto have glomerular hyperfiltration, and we note that the prevalence of diabetes and diagnoses of obesity, alcohol abuse, or chronic smoking (all of which have been suggested to increase the risk of glomerular hyperfiltration and dementia risk) were higher for this category. ${ }^{41}$ This being said, our results agree with a recent Korean study ${ }^{42}$ in which dementia risk, in particular vascular dementia, was higher in persons with eGFR above the 95th percentile of distribution compared with those in the 50th to 65th percentile.

Several plausible mechanisms explain the link between CKD and dementia. First, the shared traditional vascular risk factors of aging, hypertension, diabetes, and hypercholesterolemia lead to cerebrovascular injury, dementia, and kidney disease. ${ }^{43}$ Second, consequences of $\mathrm{CKD}$, including chronic inflammation and oxidative stress, ${ }^{44}$ endothelial abnormalities, ${ }^{45}$ disorders of the immune system, ${ }^{46}$ or hypercoagulation, ${ }^{43}$ are associated with the prevalence and occurrence of ischemic cerebrovascular lesions. Third, kidney dysfunction causes retention of uremic toxins such as cystatin C, guanidine compounds, and hyperhomocysteinemia, which results in direct neurologic toxicity to the cerebral cortex, the mammillary bodies, and the thalamus. ${ }^{47,48}$ This neurologic toxicity would lead to clinical/ subclinical disease (silent brain infarcts, microbleeds or stroke, and white matter lesions), which is known to contribute to vascular and nonvascular cognitive impairment and possibly increased dementia risk. ${ }^{11-13}$ Finally, persons with CKD have frequent microvascular and macrovascular complications, ${ }^{49}$ leading to an increased risk of cardiovascular events and stroke, ${ }^{50}$ which may be intermediates in the associations observed.

An important limitation in our study is the reliance on ICD diagnoses of dementia. ${ }^{51}$ Although the capture of these is 
estimated to be complete for our region, access to medical records would have refined the accuracy of diagnoses and probably allowed us to identify additional cases. Enriching our outcome with data on initiation of dementia medications probably improves this, but there remains a large proportion of older persons with undetected dementia living in the community, ${ }^{52}$ and the risk of misclassification bias exists. Furthermore, we rely on issued diagnoses and did not have access medical records; there may be patients thought to have dementia or predementia by their physicians who lack a diagnosis. Because the distinction of dementia types by clinical diagnoses may not always be accurate, our results concerning these may be considered hypothesis generating. For instance, patients with a history of stroke may have more often been diagnosed as having vascular dementia, and mixed Alzheimer and vascular dementia is probably more common than pure vascular dementia. Collectively, we would have benefited from confirming our diagnoses via linkage with the Swedish Dementia Register, which contains confirmation of dementia diagnoses with MiniMental State Examination score and types of dementia as confirmed by the clinician doing the examination. ${ }^{53}$ The testing of eGFR is not standardized, which may lead to detection bias (that is, patients with specific indications may be subjected to more frequent eGFR testing than others, or eGFR testing is performed as part of the workup toward a diagnosis of dementia). Our analyses excluding diagnoses within the first 2 years of follow-up or adjustment for the number of tests in the mixed model tried to evaluate the impact of these biases. Our median follow-up time can be considered short to study the overall incidence of dementia, but a longer follow-up may contribute to misclassification bias, given that kidney function also declines with time. We have no information on lifestyle, body mass index, or muscle mass, but we included clinical diagnoses of alcohol abuse, chronic smoking, and obesity. While we recognize that the sensitivity of these lifestyle-related diagnoses is low, they are highly specific and may adjust for some additional confounding. Finally, as in all observational and register-based analyses, causality cannot be inferred, and we acknowledge the existence of residual and unknown confounding, something we tried to tackle though in our sensitivity analyses.

This large health care study found an increased dementia incidence in individuals with CKD and rapid kidney function decline. Our findings may help health care policy makers to develop and implement appropriate strategies for screening and monitoring for dementia in persons with CKD (and vice versa) and assist in health service planning. On one hand, we speculate that estimating kidney function at dementia screening visits may help in risk stratification, provision of lifestyle recommendations, and perhaps consideration of cholinesterase inhibitors over other antidementia medications, given their potential kidney function-sparing effect. ${ }^{54}$ On the other hand, because awareness of CKD is still very low among patients and physicians, ${ }^{30}$ such testing may allow early identification of CKD cases who can benefit from nephrologist referral and initiation of antiproteinuric therapies (i.e., renin-angiotensin system inhibitors). We note that a recent meta-analysis of prospective cohort studies observes consistency of evidence regarding a lower dementia risk associated with the use of renin-angiotensin system inhibitors in patients with high blood pressure. ${ }^{55}$ Lifestyle habits that contribute to the prevention of cardio-cerebral vascular disease may reduce the risk of dementia and reduce the risk of CKD progression. ${ }^{7,8,56}$

\section{Acknowledgment}

This study obtained support from the Swedish Research Council (2019-01059).

\section{Study Funding}

Supported by the Swedish Research Council (2019-01059). H.X. is supported by a postdoctoral grant from Strategic Research program in Neuroscience at Karolinska Institutet.

\section{Disclosure}

B.L. is affiliated with Baxter Healthcare Corp. None of the other authors declare any conflict of interest pertinent to the present work. Go to Neurology.org/N for full disclosures.

\section{Publication History}

Received by Neurology November 6, 2020. Accepted in final form March 15, 2021.

\begin{tabular}{|c|c|c|}
\hline Name & Location & Contribution \\
\hline $\begin{array}{l}\text { Hong Xu, MD, } \\
\text { PhD }\end{array}$ & $\begin{array}{l}\text { Karolinska } \\
\text { Institutet, } \\
\text { Stockholm, Sweden }\end{array}$ & $\begin{array}{l}\text { Design and conceptualized study; } \\
\text { analyzed the data; performed } \\
\text { statistical analysis; drafted the } \\
\text { manuscript for intellectual content }\end{array}$ \\
\hline $\begin{array}{l}\text { Sara Garcia- } \\
\text { Ptacek, MD, } \\
\text { PhD }\end{array}$ & $\begin{array}{l}\text { Karolinska } \\
\text { Institutet, } \\
\text { Stockholm, Sweden }\end{array}$ & $\begin{array}{l}\text { Interpreted the data, revised the } \\
\text { manuscript for intellectual content }\end{array}$ \\
\hline $\begin{array}{l}\text { Marco } \\
\text { Trevisan, } \\
\text { Biostat }\end{array}$ & $\begin{array}{l}\text { Karolinska } \\
\text { Institutet, } \\
\text { Stockholm, Sweden }\end{array}$ & $\begin{array}{l}\text { Interpreted the data, revised the } \\
\text { manuscript for intellectual content }\end{array}$ \\
\hline $\begin{array}{l}\text { Marie Evans, } \\
\text { MD, PhD }\end{array}$ & $\begin{array}{l}\text { Karolinska } \\
\text { Institutet, } \\
\text { Stockholm, Sweden }\end{array}$ & $\begin{array}{l}\text { Interpreted the data, revised the } \\
\text { manuscript for intellectual content }\end{array}$ \\
\hline $\begin{array}{l}\text { Bengt } \\
\text { Lindholm, MD, } \\
\text { PhD }\end{array}$ & $\begin{array}{l}\text { Karolinska } \\
\text { Institutet, } \\
\text { Stockholm, Sweden }\end{array}$ & $\begin{array}{l}\text { Interpreted the data, revised the } \\
\text { manuscript for intellectual content }\end{array}$ \\
\hline $\begin{array}{l}\text { Maria } \\
\text { Eriksdotter, } \\
\text { MD, PhD }\end{array}$ & $\begin{array}{l}\text { Karolinska } \\
\text { Institutet, } \\
\text { Stockholm, Sweden }\end{array}$ & $\begin{array}{l}\text { Interpreted the data, revised the } \\
\text { manuscript for intellectual content }\end{array}$ \\
\hline $\begin{array}{l}\text { Juan Jesus } \\
\text { Carrero, } \\
\text { Pharm, PhD }\end{array}$ & $\begin{array}{l}\text { Karolinska } \\
\text { Institutet, } \\
\text { Stockholm, Sweden }\end{array}$ & $\begin{array}{l}\text { Design and conceptualized study; } \\
\text { revised the manuscript for } \\
\text { intellectual content }\end{array}$ \\
\hline
\end{tabular}

\section{References}

1. Kua EH, Ho E, Tan HH, Tsoi C, Thng C, Mahendran R. The natural history of dementia. Psychogeriatrics. 2014;14(13):196-201.

2. Prince M, Bryce R, Albanese E, Wimo A, Ribeiro W, Ferri CP. The global prevalence of dementia: a systematic review and metaanalysis. Alzheimers Dement. 2013;9(1): 63-75.e62. 
3. Clague F, Mercer SW, McLean G, Reynish E, Guthrie B. Comorbidity and polypharmacy in people with dementia: insights from a large, population-based crosssectional analysis of primary care data. Age Ageing. 2017;46(1):33-39.

4. Garcia-Ptacek S, Farahmand B, Kareholt I, Religa D, Cuadrado ML, Eriksdotter M. Mortality risk after dementia diagnosis by dementia type and underlying factors: a cohort of 15,209 patients based on the Swedish Dementia Registry. J Alzheimers Dis. 2014;41(2):467-477.

5. National Institute for Health Care and Excellence. National Institute for Health and Care Excellence: Clinical Guidelines: Dementia: Assessment, Management and Support for People Living With Dementia and Their Carers. National Institute for Health and Care Excellence; 2018.

6. Eckardt KU, Coresh J, Devuyst O, et al. Evolving importance of kidney disease: from subspecialty to global health burden. Lancet. 2013;382(9887):158-169.

7. Gansevoort RT, Correa-Rotter R, Hemmelgarn BR, et al. Chronic kidney disease and cardiovascular risk: epidemiology, mechanisms, and prevention. Lancet. 2013; 382(9889):339-352.

8. Masson P, Webster AC, Hong M, Turner R, Lindley RI, Craig JC. Chronic kidney disease and the risk of stroke: a systematic review and meta-analysis. Nephrol Dial Transplant. 2015;30(7):1162-1169.

9. $\mathrm{Xu} \mathrm{H}$, Gasparini A, Ishigami J, et al. eGFR and the risk of community-acquired infections. Clin J Am Soc Nephrol. 2017;12(9):1399-1408.

10. Astor BC, Muntner P, Levin A, Eustace JA, Coresh J. Association of kidney function with anemia: the third National Health and Nutrition Examination Survey (19881994). Arch Intern Med. 2002;162(12):1401-1408.

11. Etgen T. Kidney disease as a determinant of cognitive decline and dementia. Alzheimers Res Ther. 2015;7(1):29.

12. Zammit AR, Katz MJ, Bitzer M, Lipton RB. Cognitive impairment and dementia in older adults with chronic kidney disease: a review. Alzheimer Dis Assoc Disord. 2016; 30(4):357-366

13. Bugnicourt JM, Godefroy O, Chillon JM, Choukroun G, Massy ZA. Cognitive disorders and dementia in CKD: the neglected kidney-brain axis. J Am Soc Nephrol. 2013; 24(3):353-363.

14. Berger I, Wu S, Masson P, et al. Cognition in chronic kidney disease: a systematic review and meta-analysis. BMC Med. 2016;14(1):206.

15. Vanderlinden JA, Ross-White A, Holden R, Shamseddin MK, Day A, Boyd JG. Quantifying cognitive dysfunction across the spectrum of end-stage kidney disease: a systematic review and meta-analysis. Nephrology. 2019;24(1):5-16.

16. O'Lone E, Connors M, Masson P, et al. Cognition in people with end-stage kidney disease treated with hemodialysis: a systematic review and meta-analysis. Am J Kidney Dis. 2016;67(6):925-935.

17. Tian X, Guo X, Xia X, Yu H, Li X, Jiang A. The comparison of cognitive function and risk of dementia in CKD patients under peritoneal dialysis and hemodialysis: a PRISMAcompliant systematic review and meta-analysis. Medicine. 2019;98(6):e14390.

18. Etgen T, Chonchol M, Förstl H, Sander D. Chronic kidney disease and cognitive impairment: a systematic review and meta-analysis. Am J Nephrol. 2012;35(5):474-482

19. Seliger SL, Siscovick DS, Stehman-Breen CO, et al. Moderate renal impairment and risk of dementia among older adults: the Cardiovascular Health Cognition Study. J Am Soc Nephrol. 2004;15(7):1904-1911.

20. Miwa $\mathrm{K}$, Tanaka M, Okazaki S, et al. Chronic kidney disease is associated with dementia independent of cerebral small-vessel disease. Neurology. 2014;82(12):1051-1057.

21. Sasaki Y, Marioni R, Kasai M, Ishii H, Yamaguchi S, Meguro K. Chronic kidney disease: a risk factor for dementia onset: a population-based study: the Osaki-Tajiri Project. J Am Geriatr Soc. 2011;59(7):1175-1181

22. Sundelöf J, Arnlöv J, Ingelsson E, et al. Serum cystatin C and the risk of Alzheimer disease in elderly men. Neurology. 2008;71(14):1072-1079.

23. Helmer C, Stengel B, Metzger M, et al. Chronic kidney disease, cognitive decline, and incident dementia: the 3C Study. Neurology. 2011;77(23):2043-2051.

24. Lipnicki DM, Sachdev PS, Crawford J, et al. Risk factors for late-life cognitive decline and variation with age and sex in the Sydney Memory and Ageing Study. PLoS One. 2013;8(6):e65841.

25. O'Hare AM, Walker R, Haneuse S, et al. Relationship between longitudinal measure of renal function and onset of dementia in a community cohort of older adults. J Am Geriatr Soc. 2012;60(12):2215-2222

26. Deckers K, Camerino I, van Boxtel MP, et al. Dementia risk in renal dysfunction: systematic review and meta-analysis of prospective studies. Neurology. 2017;88(2):198-208.

27. Takae K, Hata J, Ohara T, et al. Albuminuria increases the risks for both Alzheimer disease and vascular dementia in community-dwelling Japanese elderly: the Hisayama study. J Am Heart Assoc. 2018;7(2):e006693.

28. Gabin JM, Romundstad S, Saltvedt I, Holmen J. Moderately increased albuminuria, chronic kidney disease and incident dementia: the HUNT study. BMC Nephrol. 2019;20:261.
29. Higuchi M, Chen R, Abbott RD, et al. Mid-life proteinuria and late-life cognitive function and dementia in elderly men: the Honolulu-Asia Aging Study. Alzheimer Dis Assoc Disord. 2015;29(3):200-205.

30. Runesson B, Gasparini A, Qureshi AR, et al. The Stockholm CREAtinine Measurements (SCREAM) project: protocol overview and regional representativeness. Clin Kidney J. 2016;9(1):119-127.

31. Levey AS, Stevens LA, Schmid CH, et al. A new equation to estimate glomerular filtration rate. Ann Intern Med. 2009;150(9):604-612.

32. Matsushita K, van der Velde M, Astor BC, et al. Association of estimated glomerular filtration rate and albuminuria with all-cause and cardiovascular mortality in general population cohorts: a collaborative meta-analysis. Lancet. 2010;375(9731): 2073-2081.

33. Gansevoort RT, Matsushita K, van der Velde M, et al. Lower estimated GFR and higher albuminuria are associated with adverse kidney outcomes: a collaborative metaanalysis of general and high-risk population cohorts. Kidney Int. 2011;80(1):93-104.

34. Sjolander A. Estimation of causal effect measures with the R-package stdReg. Eur J Epidemiol. 2018;33(9):847-858.

35. Jin YP, Gatz M, Johansson B, Pedersen NL. Sensitivity and specificity of dementia coding in two Swedish disease registries. Neurology. 2004;63(4):739-741.

36. Kurella Tamura M, Gaussoin SA, Pajewski NM, et al. Kidney disease, intensive hypertension treatment, and risk for dementia and mild cognitive impairment: the Systolic Blood Pressure Intervention Trial. J Am Soc Nephrol. 2020;31(9):2122-2132.

37. Soveri I, Berg UB, Bjork J, et al. Measuring GFR: a systematic review. Am J Kidney Dis. 2014;64(3):411-424.

38. Garcia-Ptacek S, Matias-Guiu JA, Valencia-Sanchez C, et al. Mechanical endovascula treatment of acute stroke due to cardiac myxoma. J Neurointerv Surg. 2014;6(1):e1.

39. Garcia-Ptacek S, Kareholt I, Farahmand B, Cuadrado ML, Religa D, Eriksdotter M. Body-mass index and mortality in incident dementia: a cohort study on 11,398 patients from SveDem, the Swedish Dementia Registry. J Am Med Dir Assoc. 2014; 15(6):447.e441-447.

40. Waite SJ, Maitland S, Thomas A, Yarnall AJ. Sarcopenia and frailty in individuals with dementia: a systematic review. Arch Gerontol Geriatr. 2021;92:104268.

41. Livingston G, Huntley J, Sommerlad A, et al. Dementia prevention, intervention, and care: 2020 report of the Lancet Commission. Lancet 2020;396(10248):413-446.

42. Kang MW, Park S, Lee S, et al. Glomerular hyperfiltration is associated with dementia: a nationwide population-based study. PLoS One. 2020;15(1):e0228361.

43. Toyoda K, Ninomiya T. Stroke and cerebrovascular diseases in patients with chronic kidney disease. Lancet Neurol. 2014;13(8):823-833.

44. Carrero JJ, Stenvinkel P. Inflammation in end-stage renal disease: what have we learned in 10 years? Semin Dial. 2010;23(5):498-509.

45. Tomiyama H, Yamashina A. Clinical considerations for the association between vascular damage and chronic kidney disease. Pulse (Basel). 2014;2(1-4):81-94.

46. Kato $\mathrm{S}$, Chmielewski $\mathrm{M}$, Honda $\mathrm{H}$, et al. Aspects of immune dysfunction in end-stage renal disease. Clin J Am Soc Nephrol. 2008;3(5):1526-1533.

47. Seifter JL, Samuels MA. Uremic encephalopathy and other brain disorders associated with renal failure. Semin Neurol. 2011;31(2):139-143.

48. Yaffe $\mathrm{K}$, Lindquist $\mathrm{K}$, Shlipak MG, et al. Cystatin $\mathrm{C}$ as a marker of cognitive function in elders: findings from the Health ABC Study. Ann Neurol. 2008;63(6):798-802.

49. Kelly DM, Rothwell PM. Prevention and treatment of stroke in patients with chronic kidney disease: an overview of evidence and current guidelines. Kidney Int. 2020; 97(2):266-278.

50. Lee M, Saver JL, Chang KH, Liao HW, Chang SC, Ovbiagele B. Low glomerular filtration rate and risk of stroke: meta-analysis. BMJ. 2010;341:c4249.

51. Rizzuto D, Feldman AL, Karlsson IK, Dahl Aslan AK, Gatz M, Pedersen NL. Detection of dementia cases in two Swedish health registers: a validation study. J Alzheimers Dis. 2018;61(4):1301-1310.

52. Sternberg SA, Wershof Schwartz A, Karunananthan S, Bergman H, Mark Clarfield A. The identification of frailty: a systematic literature review. J Am Geriatr Soc. 2011 59(11):2129-2138

53. Religa D, Fereshtehnejad SM, Cermakova P, et al. SveDem, the Swedish Dementia Registry: a tool for improving the quality of diagnostics, treatment and care of dementia patients in clinical practice. PLoS One. 2015;10(2):e0116538.

54. Nordström P, Religa D, Wimo A, Winblad B, Eriksdotter M. The use of cholinesterase inhibitors and the risk of myocardial infarction and death: a nationwide cohort study in subjects with Alzheimer's disease. Eur Heart J. 2013;34(33):2585-2591.

55. Ding J, Davis-Plourde KL, Sedaghat S, et al. Antihypertensive medications and risk for incident dementia and Alzheimer's disease: a meta-analysis of individual participant data from prospective cohort studies. Lancet Neurol. 2020;19(1):61-70.

56. Kelly JT, Su G, Zhang L, et al. Modifiable lifestyle factors for primary prevention of CKD: a systematic review and meta-analysis. J Am Soc Nephrol. 2021;32(1):239-253. 


\section{Neurology}

\section{Kidney Function, Kidney Function Decline, and the Risk of Dementia in Older Adults: A Registry-Based Study \\ Hong Xu, Sara Garcia-Ptacek, Marco Trevisan, et al.}

Neurology 2021;96;e2956-e2965 Published Online before print May 5, 2021

DOI 10.1212/WNL.0000000000012113

\section{This information is current as of May 5, 2021}

\section{Updated Information \& Services}

References

Citations

Subspecialty Collections

Permissions \& Licensing

Reprints including high resolution figures, can be found at: http://n.neurology.org/content/96/24/e2956.full

This article cites 55 articles, 14 of which you can access for free at: http://n.neurology.org/content/96/24/e2956.full\#ref-list-1

This article has been cited by 2 HighWire-hosted articles: http://n.neurology.org/content/96/24/e2956.full\#\#otherarticles

This article, along with others on similar topics, appears in the following collection(s):

All Cognitive Disorders/Dementia

http://n.neurology.org/cgi/collection/all_cognitive_disorders_dementia Alzheimer's disease

http://n.neurology.org/cgi/collection/alzheimers_disease

Cohort studies

http://n.neurology.org/cgi/collection/cohort_studies

Vascular dementia

http://n.neurology.org/cgi/collection/vascular_dementia

Information about reproducing this article in parts (figures,tables) or in its entirety can be found online at:

http://www.neurology.org/about/about_the_journal\#permissions

Information about ordering reprints can be found online:

http://n.neurology.org/subscribers/advertise

Neurology ${ }^{\circledR}$ is the official journal of the American Academy of Neurology. Published continuously since 1951, it is now a weekly with 48 issues per year. Copyright Copyright ( 2021 The Author(s). Published by Wolters Kluwer Health, Inc. on behalf of the American Academy of Neurology.. All rights reserved. Print ISSN: 0028-3878. Online ISSN: 1526-632X.

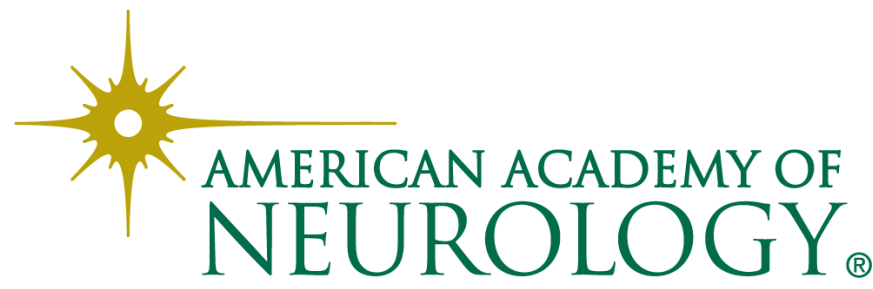

